RESEARCH PAPER

\title{
Exploring Women Representation in Meme Discourse: A Multimodal Critical Discourse Analysis of Selected Memes from Pakistani Facebook Pages
}

\author{
1Amna Shahid 2Dr. Humaira Irfan* ${ }^{3}$ Qaisar Abbas
}

1. PhD English Scholar, Department of English, Division of Arts \& Social Sciences, University of Education, Lahore, Punjab, Pakistan

2. Department of English, Division of Arts and Social Sciences, University of Education, Lahore, Punjab, Pakistan

3. BS Honors, Department of Language and Literature, University of the Punjab, Lahore, Punjab, Pakistan

\begin{tabular}{|c|c|}
\hline PAP & \\
\hline & \multirow{3}{*}{$\begin{array}{l}\text { Today, creating, viewing, and sharing memes has become a daily } \\
\text { activity for many users on the social media, especially Facebook. This } \\
\text { study analyzes women representation in meme discourse. The study } \\
\text { aims to investigate how women are represented in the memes of } \\
\text { Pakistani Facebook pages. It has particularly focused how women are } \\
\text { linguistically and visually portrayed in the memes. Also, the study has } \\
\text { identified stereotyping about women in Pakistani context. For } \\
\text { investigating women representation in memes, } 6 \text { popular internet } \\
\text { memes had been selected from three Pakistani Facebook Pages, } \\
\text { Lateefon Ki Dunay, Mangobaz and Sarcamistan. To explore women } \\
\text { representation in the memes, Multimodal Critical Discourse Analysis } \\
\text { was applied as a theoretical framework. The findings of the study } \\
\text { revealed that women are represented in negative manners in } \\
\text { Pakistani Facebook pages. Moreover, the memes maintains the } \\
\text { stereotypical representation of women. The study concluded that } \\
\text { such stereotypes and negativity about women should be eliminated } \\
\text { by educating people, especially men. }\end{array}$} \\
\hline & \\
\hline & \\
\hline
\end{tabular}

\section{Introduction}

Today social media has become an integral part of everyday life and it has strong influence on social and private life. Though online and offline interaction, people significantly participate in social media by sharing their everyday practices and experiences. The use and the influence of social media have increased rapidly with the rise of social networking sites, especially Facebook. Currently Facebook is the most popular and the biggest social networking site in the world, with nearly 2.45 million active users (Aboulhosn, 2020). Similarly, in Pakistan, Facebook is the most popular social networking site with 92.06\% active users among internet users (AlphaPro, 2018, Para. 1).Considering the tremendous popularity of Facebook, it is fruitful to study Facebook. Therefore, this research paper explores Facebook memes to investigate women representation in Pakistani context. Facebook users participate in online activities in various ways such as posting their thoughts and opinions, exchanging photos, sharing news and stories, and participating in online discussions. However, currently the browsing of memes is seen as the most popular activity on social media, especially Facebook (Rakib, 2019). Creating, 
viewing, and sharing memes has become a daily activity for many users, especially for youngsters (Irfan, 2018).

The term meme, coined by Richard Dawkins, refers to the "small cultural units of transmission, analogous to genes, which are spread from person to person by copying or imitation" (Shifman, 2013). Ideas, gestures, signs, melodies, catchy-phrases, clothes fashions, religion, science, and politics are the examples of meme. However, the concept of meme has changed with the development and advancement of technology. According to Davison (2012), the term internet meme refers to "a piece of culture, typically a joke, which gains influence through the online transmission" (p.122). Humor is commonly found in all internet memes. Internet memes are shared ubiquitously on the social media such as Facebook. They have become "the hallmark of $21^{\text {st }}$ century" in online culture of social media. They are the essential part of contemporary social media culture. There are specifically memes pages, such as Facebook memes pages Mangobaz, Sarcasmistan, Lateffon Ki Dunya, dedicated exclusively to generating and circulating memes on social media. Enjoying and sharing memes with others has become a universal norm on social media, especially Facebook (Ding, 2015). On daily basis, thousands of memes are created and shared. These memes usually joke at others (Irfan, 2021).

Multimodal discourse is a kind of discourse communicated through more than a single mode (Fairclough, 2001; Kress, 2009). Nowadays, multimodal discourse is becoming increasingly important due to the ubiquitous prevalence on the internet, which combines several modes, such as text, picture, music, video, for communication. The term multimodal refers to the combination and integration of different modes, for example language and picture, which form a given discourse or a kind of discourse (Leeuwen, 2015). In other words, picture-text combination is a kind of multimodal discourse which is a mixture of two modes, namely, picture and text. Internet meme discourse is multimodal discourse, a combination text and picture. Therefore, the study will apply Multimodal Critical Discourse Analysis (MCDA) to investigate women representation in the memes.

The study aims to analyze women representation in the memes of Pakistani Facebook Pages, and to investigate how women are linguistically and visually portrayed in the memes, through the lens of Multimodal Critical Discourse Analysis.

\section{Literature Review}

The term "meme" was originated in 1976, by Richard Dawkins. The concept of "meme" has been conceived and defined differently by different scholars and researchers. There are two perspectives in defining memes, meme as a unit of culture, and meme as an internet artifact. Dawkins' idea of meme is the notion of "replicators". He points out that memes replicate themselves "in the meme pool by leaping from brain to brain via a process of imitation (Dawkins, 1976). Dawkins (1976) defined three characteristics of a successful meme: fidelity, refers to the idea of accurate transmission from an individual to another; fecundity, indicates the fact of rate at which memes are copied or circulated; and longevity, refers to the time duration in which the meme is survived in a chain of circulation process. The concept of meme has been modified with the evolution of technology. According to Lombard, "the internet has provided the most fertile environment for replication to date" (2014, p. 21). According to Davison (2012), the term internet meme refers to "a piece of culture, typically a joke, which gains influence through the online transmission" In other words, internet meme is a phrase, image or video circulated the internet. Another researcher, Shifman articulates that internet memes "describe the propagation as content 
items such as jokes, rumors, videos, or websites from one person to another via the internet" (2013, p. 362).

In Pakistan, Facebook is the most popular social networking site whose users are still increasing with every passing second. Latest statics shows that, $92.06 \%$ people are actively using Facebook in Pakistan (AlphaPro, 2018). There are several distinctive pages on Facebook with millions of followers for memes sharing.For example, Lateefon Ki Dunya, Mangobaaz and Sarcamistan are three popular Pakistani memes promoters Facebook pages with millions of followers. Currently, these three pages have 11 million followers on Facebook. It implies that if a meme is shared on these pages, it will potentially be exposed to 11 million people simultaneously the meme is further shared to the whole world within seconds. Today, memes sharing has become "the hallmark of $21^{\text {st }}$ century" in online culture of social media (Bereheny, 2016), which leads to online discourse of internet memes as a distinctive social discourse.

Siddique et al. (2018) investigated the spread of sexism via internet memes. The study reveals that sexist memes perpetuate gender stereotypes. Women are attributed with adjective such as bitchy, stupid, inferior, and uneducated. Drakett et al. (2018) analyzed the online harassment of women and marginalized groups in the internet memes. He found that online sexism and harassment are often accepted by reframing in the form of humor. Women representation in the internet memes is damaging as issues such as sexual assault and domestic violence are justified with the help of joking. A study was carried out on internet memes in Japanese context to investigate how women have been secluded, suppressed, and silenced at the highest level of society in Imperial Japan. The researcher argued that women response to the oppression is also shaped by the memes. It concluded that memes can be used as a tool challenging social oppression.

It could be seen that several studies have been carried out on the internet memes and women representation. However, in the context of Pakistan, where misrepresentation of women and stereotyping about women has been prevailing for decades, there has been absolutely no attention paid to the rising popularity of internet memes that target women. Therefore, it is a dire need to pay attention to the rising phenomenon of internet meme discourse and women representation in Pakistani context. So, this study will fill the gap by addressing FB memes and women representation, in Pakistani context; by using multimodal discourse approach. Critical discourse analysis (CDA) is a kind of analysis which investigates written or spoken texts to uncover the existence of power, inequality, hegemony and the ideological assumption rooted in the linguistic structure of texts (Machin \& Mayer, 2012).

Fairclough points out that discourse analysis is a critical approach as it involves having distance from data and doing analysis objectively (Jhedi, 2014). Van Dijk's(2001) approach focuses on the relationship between micro-structure of language and the macrostructure of society Micro level refers to the usage of language, discourse, and communication, whereas macro level refers to inequalities and power relations among social groups. The term multimodal refers to the combination and integration of different modes, for example language and picture, which form a given discourse or a kind of discourse. For example, picture-text combination is a kind of multimodal discourse which is a mixture of two modes, picture, and text. Multimodal discourse combines several modes, such as text, picture, music, video, for communication (Leeuwen, 2015). 


\section{Material and Methods}

\section{Data Collection}

In this study the research data was comprised of internet memes taken from Facebook.16 internet memes had been selected from three Pakistani Facebook pages, namely Lateefon Ki Dunya, Mangobaaz and Sarcamistan. There were some limitations to this study. Firstly, for investigating women representation, this study had analyzed only visual and textual content of Facebook memes without analyzing captions and comments of the memes. secondly, the corpus of memes was small. If the true representation of Pakistani women has to be determined in memes, then an extensive corpus of memes, from a wide range of sources, would be required.

\section{Data Analysis}

The micro level, the term text not only applies to linguistic features of a text, but it also applies to visual features, like image, color, signs (Vahid, 2012). Therefore, at this level linguistic features and visual features of each internet meme are analyzed. The textual analysis fulfills the first question of the research which deals with how women are presented linguistically and visually in the memes of Pakistani Facebook pages.

\section{Results and Discussion}

\section{Analysis of Memes}

Following pictures depict the analysis of memes.

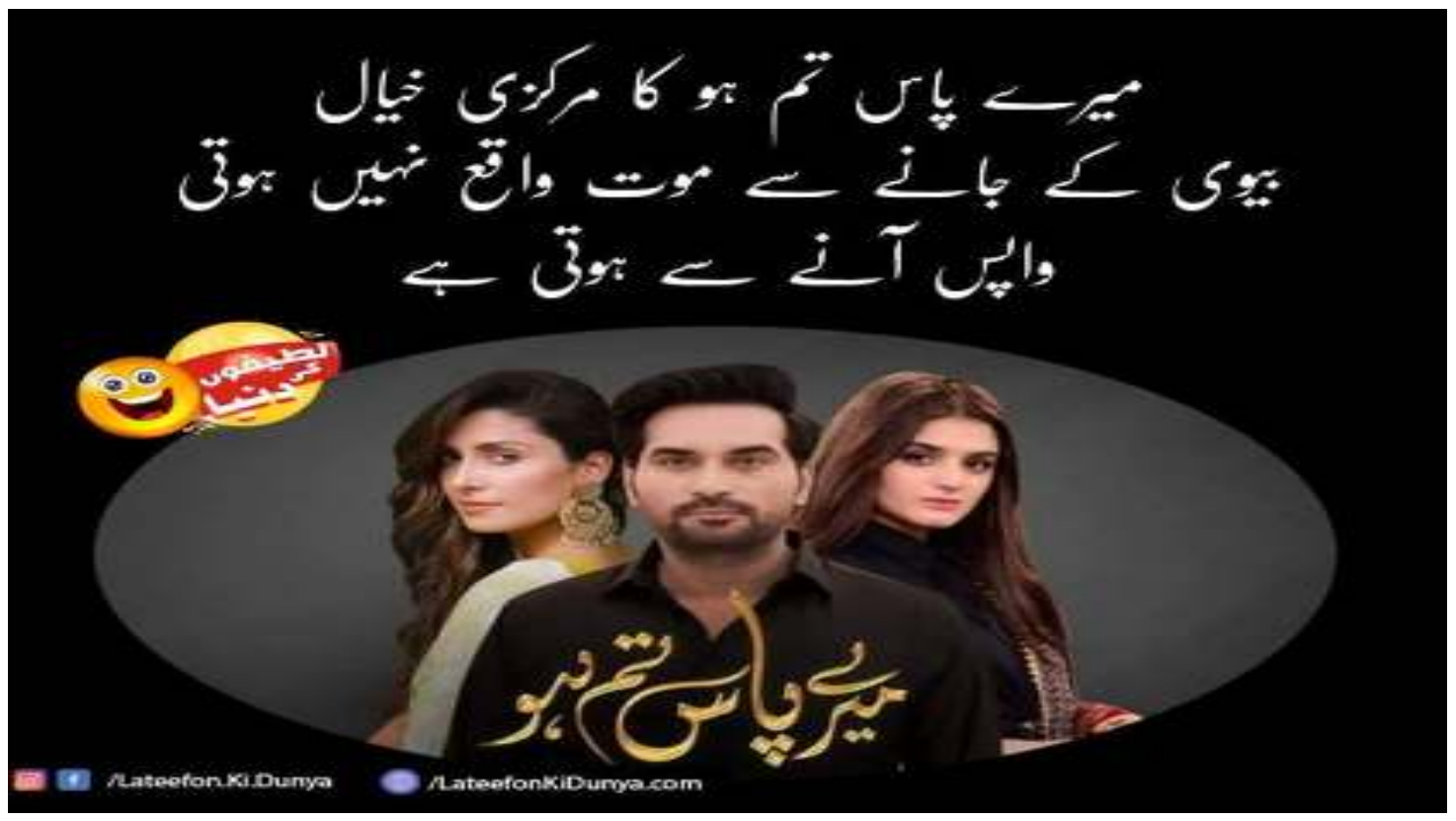

Image 1. Analysis of Meme 1

Translation: The Analysis of Meme 1 central theme of the drama "Meray Pas Tum Ho": One does not die because of the departure of wife, but because of the arrival of wife. This meme is based on Pakistani drama "Meray Pas Tum Ho" which is purely based on patriarchal structure. There are two sentences in the memes, focusing on wife's character. 
The first line of the meme, "the central theme of the drama", attracts reader toward it. In the title of the drama, (translation) "I have you" two personal pronouns are used "I and You". Personal pronoun "I," used for the male actor, shows the authority over "you," the women. It shows that the wife is something of possession owned by the husband. In the second sentence death is associated with wife's arrival, while the concept of happy life is associated with her departure. These lines present the women character negatively. In the image the male actor is standing in front of two female actors. The image is static in which participants are involved in narrative process in which reactions of the represented participants are shown. The image is demand as the participants are directly gazing at the viewers (Kress \& van Leeuwen, 2006). The stare of the participants is cold show the inferiority of the participants. The social distance between the participants and the viewers is social as the participants are shown from head to the shoulder. The image creates involvement with the viewers. The black colour in the background is associated with the theme of death. Overall, the language of the meme is explicitly favoring the patriarchal gendered norms and values. Women are directly subjected, and their arrival is compared with death. It perpetuates the stereotypical notion about women that women as a wife are troublesome creature.

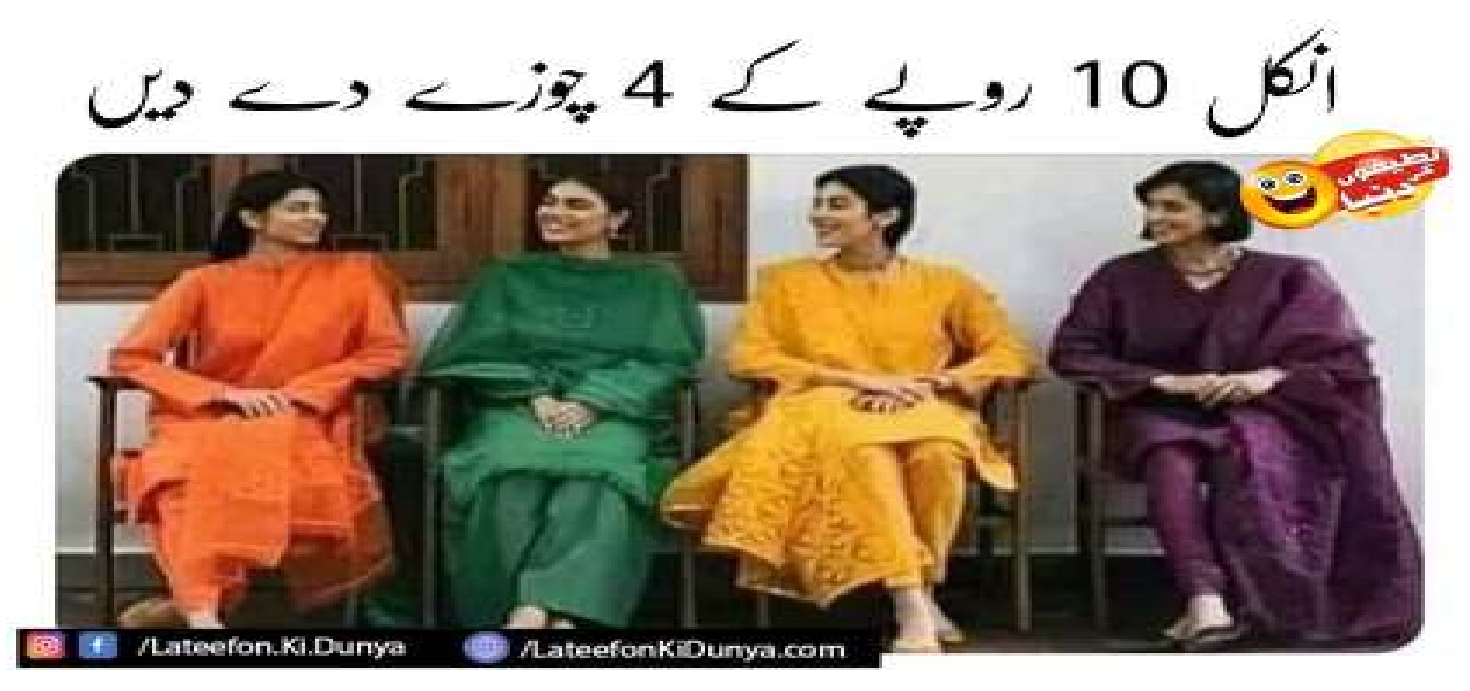

Image 2. Analysis of Meme 2

Translation: Uncle! Give four chicks for ten rupees. The meme has only one sentence which is imperative. According to Fairclough (2001), imperative sentences are used to persuade the readers to accept something. The important word is a noun "chick", which is a metaphor used for women. It compares them with the characteristics of chicks who always whistle. The figure four with chick's covey the idea of four wives. In the image four women are sitting on the chair and talking to each other. The image involves narrative process as the participants are reacting to each other. At eye contact level, the image is an offer image as it offers the participants as an object of information to the viewers. At the social distance level, the image is impersonal because it detaches viewers (especially men) from the represented participants. Overall, the meme constructs and promotes the image of women as talkative which is the most common stereotype about women. 


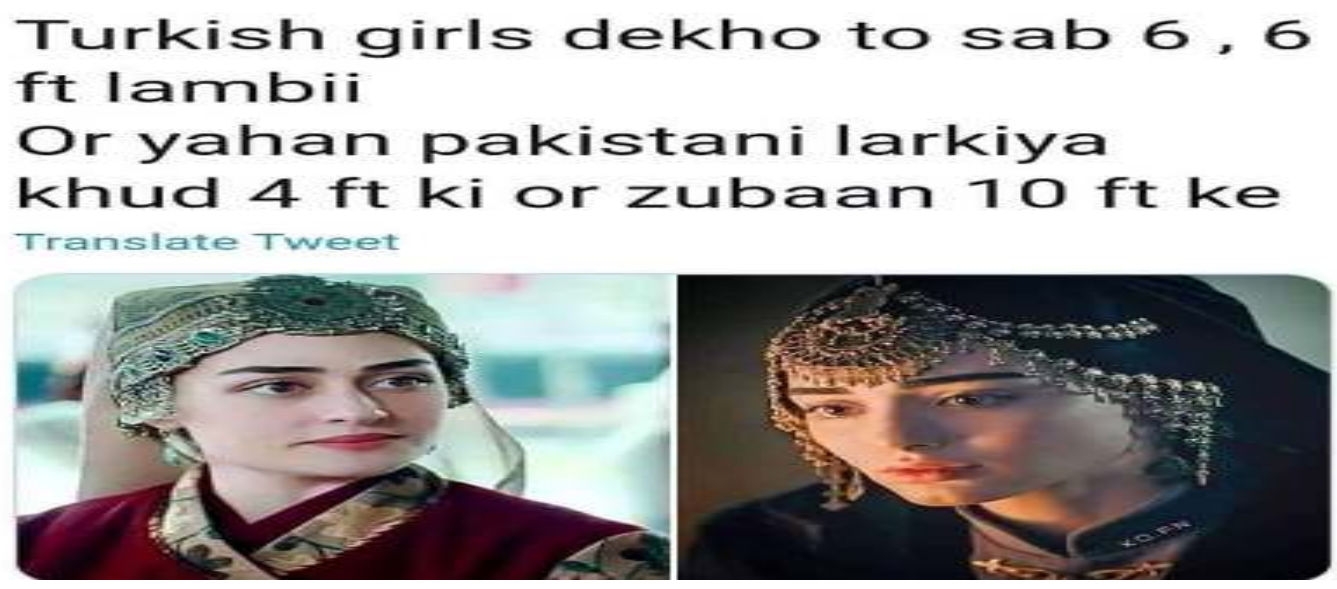

Image 3. Analysis of Meme 3

Translation: All Turkish girls are tall, having 6 feet height; and, here, in Pakistan, all girls are four feet themselves, but their tongue is ten feet long. This meme makes a comparison between Turkish and Pakistani girls. There is one sentence with two clauses, joined by and, in the meme. The sentence is in declarative mood which persuades the reader to accept the idea as truth. The first clause describes Turkish girls in the terms of height by attributing two adjectives with them. According to Fairclough, adjectives show positivity or negativity about something (2001). "Tall" and "six feet" height is attributed with Turkish girls in the meme. In the second clause, Pakistani girls are compared with Turkish girls. Two phrases "four feet height" and "ten feet tongue" describe Pakistani women. A significant word is an adjective "all" which generalizes all women. At the visual level, there are two images of a female are shown in the picture. In the terms of eye contact the image can be categorized as an offer image which offers two females as an object of contemplation to the viewers. In the term of social distance, it shows an intimate relationship as women shoulders and heads are visible (Kress, 2009).Overall, the meme presents women in negative manners. Women are stereotyped in terms of height and talkativeness using exaggerated terms.

\section{Ayeshay \\ @champagne_lassi}

\section{when you go to family gatherings for free food, but end up getting comments on your weight height skin by aunties}

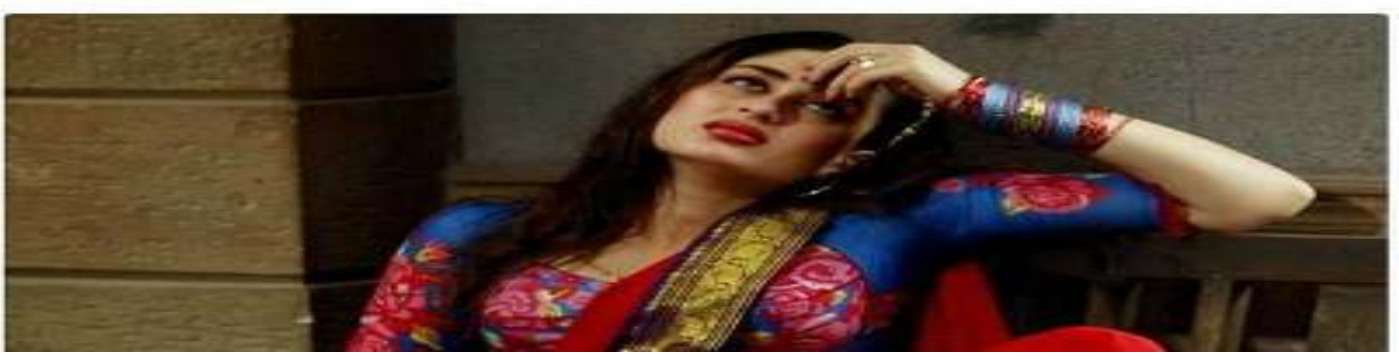

Image 4. Analysis of Meme 4 
The above meme is about an upset woman who is a subject of discussion in family gatherings. The first clause starts with an adverb when, which describes the situation for understanding meme. Second clause describes what happened in that situation. Personal pronouns "you," and "your" specifically refer to women to imagine the situation. The phrase "family gatherings" is symbolic as it suggests the idea of public gatherings. The second clause has three most important lexical words "weight, height and skin" used for women. These three words show that women are judged by their physical appearance. In the image, there is one participant, a girl, who seems sad. The image has narrative process in which a girl is reacting sadly. At eye contact level, the image seems an offer image which offers the viewers to examine the feeling of the represented participant. In the image, the face and the shoulders of the girl are visible that shows a personal relationship with the viewers (Kress \& van Leeuwen, 2006). The meme reflects the social behavior towards women where women are judged by their appearance. Stereotyping about women appearance is encoded and created linguistically and visually in the meme.

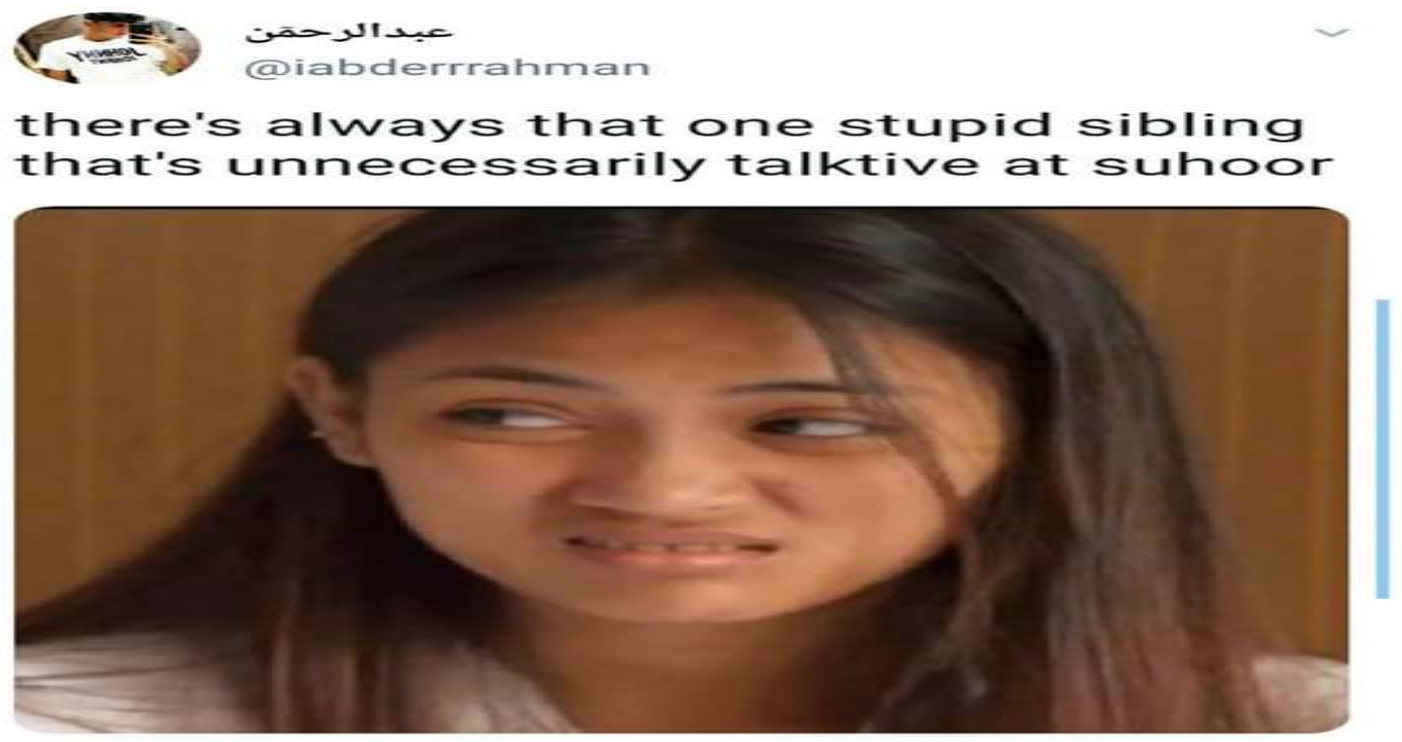

Image 5. Analysis of Meme 5

This meme manipulates women as stupid and talkative creature. The sentence is declarative having two clauses, one is the simple and the other one is relative clause. According to the Fairclough (2001), declarative sentence directly persuades the reader to accept the idea. An adverb "always" is used in the sentence to further strengthen the idea. There are two adjectives "stupid" and "talkative" used for women identity. These two adjectives create the negative image of women. This sentence is not separated from the image, rather it is meaningful with the image. In the image a girl is watching offensively. At the representational level, the image can be described as narrative as the reaction of the girl is shown in the image. At interactional level, the image is an offer image because it offers the contemplation to the viewers. In the term of social contact, the image creates personal relation with the viwers. The image creates personal image as it involves close shot (Kress \& van Leeuwen, 2006). Women are manipulated as stupid and talkitive creature. The analysis shows that this meme perpeuates and projects women as stupid and talkative. 


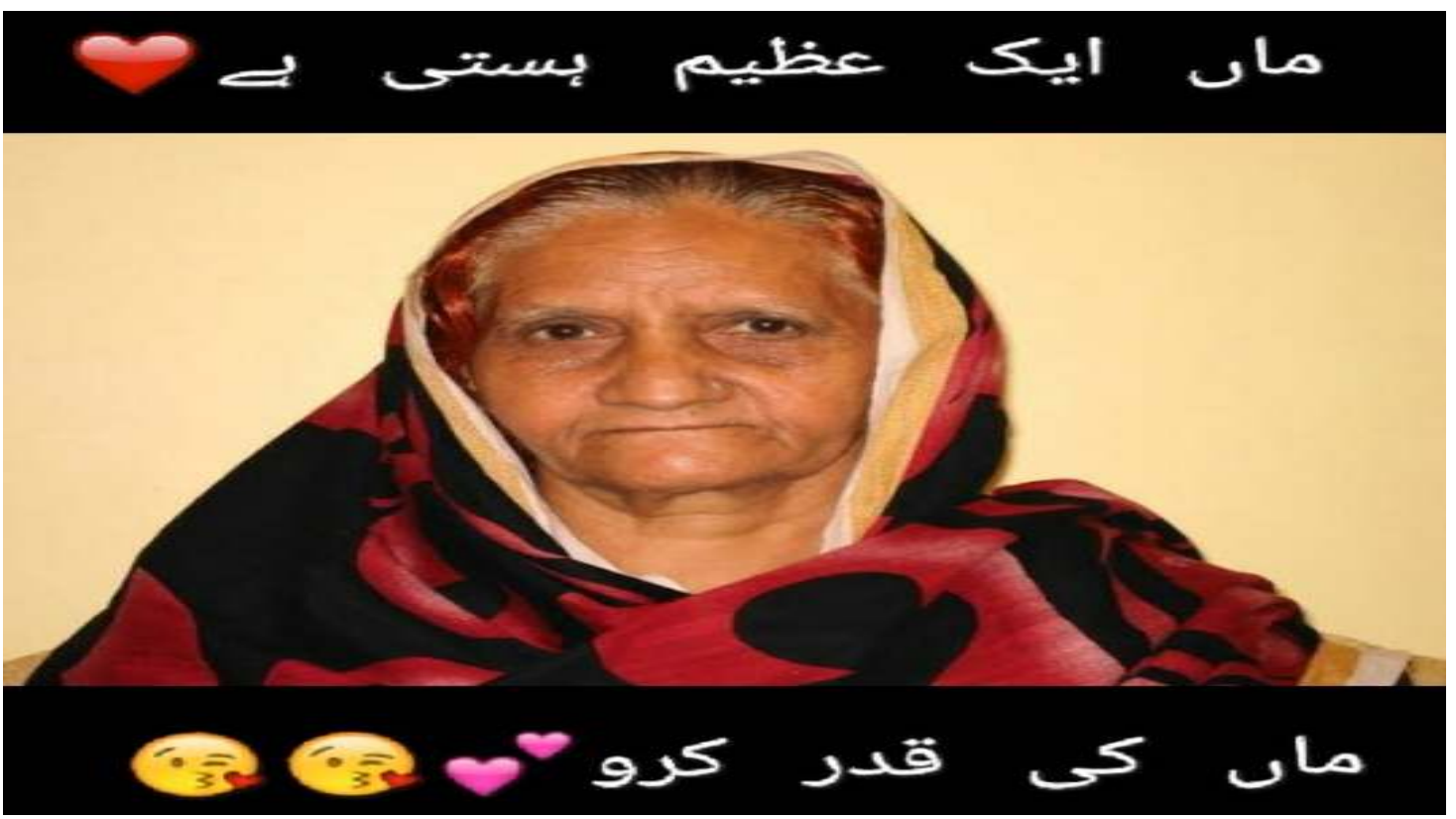

Image 6. Analysis of Meme 6

Translation: Mother is a great being Respect your mother. The above meme portrays mothers as a great being. The first sentence is declarative which persuades the reader to accept the idea. Women are presented as "a great being. It is important to note that this is the only category which presents women positively. The second sentence is imperative which stresses that always respect you mother. This meme explicitly projects women as "a great being". There is an image of female is shown in the image. According to Kress \& van Leeuwen's framework (2006), representation of the image involves narrative process in which a woman is shown. The image of the woman is static as there is no action performance. In the term of interaction, the mage is a demand image which demands the viewers to imagine the represented role. The meme reflects women positively. It creates positive image of women as a mother. This is the only category which presents women positively.

\section{Discursive Analysis}

This study mainly focuses on discursive strategies used in the Facebook memes to represent women and to make them acceptable. There are several discursive practices, such as women image, positive self-presentation and negative other presentation, code switching, use of metaphors and humorous emojis, are used in the memes for constructing stereotyping about women and their acceptance. In most of the memes, women imagesare shown to capture the attention of the viewers.In most of the memes, women are stereotyped in the images. The positive self-presentation and negative other representation strategy is also used. The third strategy which is used in the memes is code switching. It occurred in many memes as they are written in Urdu and English. Use of metaphors is also realized in memes to represent women. Women are compared with other object for showing similarity. The strategy of collectivization is used in memes, such as "girls, Pakistani girls" (see Meme 3). All these discursive strategies are used in the memes to represent and stereotype women. 


\section{Social Analysis}

Social analysis examines the relationship between discourse and social structure. It explains "discourse as a sociocultural practice" (Handyani et al., 2018). Through the lens of Fairclough's 3D modal, social analysis investigates the socio context in which memes are produced. Textual analysis revealed that Facebook memes represent women negatively and maintain stereotyping about them. These findings are relevant to the socio-context of Pakistan. The analyzed memes show the general mindset of Pakistani men about women. Pakistan is a patriarchal society in which patriarchal social norms are strictly followed. According to Noor (2015) "Pakistan falls 'within the belt of classic patriarchy' where there is "a culture against women". Patriarchal society teaches women to follow patriarchal codes of society in which different social discourse, like meme discourse, are purposively used to maintain patriarchal social norms. These memes fulfill patriarchal ideology of Pakistanis about women. Women portrayal in memes may serve as expectations from Pakistani society as they are purposefully constructed. Stereotypes about women depict them as talkative, irrational, troublesome, selfish, housewives and an object of entertainment and satisfaction. Moreover, women are compared with animals which dehumanize and objectify them. So, the memes depict Pakistani women in negative manners, which directly or indirectly perpetuating stereotypes about women for the survival of patriarchal society.

\section{Interpretation of Findings and Discussion}

It is found that women representation in memes of Pakistani Facebook pages is negative. The data analysis shows that negative representation of women is not only codified linguistically, but it is also enriched and created visually. Another important aspect is that stereotyping about women is remained unchanged on Facebook. This study supports Linclon' view that stereotypical gender representations in memes with underrepresentation of women are maintained (2019). Memes are used to construct and maintain the stereotypical image of women which remained dominant in most of the memes. The textual analyses revealed that both linguistic and visual content of the memes encode women negatively. Linguistic description of the memes remained dominant for negative representations of women. Depreciating language in the form of memes, with images, is used as a medium to misrepresent women (Siddique et al, 2018). The linguistic analysis has proved that language play a vital role creating and perpetuating underrepresentation of women. In the description stage, the researcher has done systematic analysis of linguistic features such as vocabulary, grammar, syntax, and rhetorical devices. Through the choice of different words, such as adjective, verb, adverb, and the grammar, women are manipulated in negative manners. Specifically, the choice of vocabulary is a powerful tool for expressing ideology about women (Fairclough, 2001).In this study, vocabulary of the memes has provided an important understanding of how women are manifested in memes on Facebook. In the social analysis stage, it is found that memes of Pakistani Facebook pages negatively represent women of Pakistan. Moreover, Facebook memes represent women maintain stereotyping about them. The findings of this study are relevant to the socio-context of Pakistan. Pakistan is a patriarchal society in which patriarchal social norms are strictly followed. It teaches women to follow patriarchal codes of society where different social discourse, like meme discourse, is purposively used to maintain patriarchal social norms. The analyzed memes construct and perpetuate social structures of Pakistani society to maintain patriarchy. According to the data analysis, women are portrayed negatively. Memes perpetuate patriarchy and stereotypes about women and depict them as talkative, irrational, troublesome, selfish, housewives and an object of entertainment and satisfaction. Moreover, women are compared with animals which dehumanize and objectify them. So, the memes depict Pakistani women in negative manners, which directly or indirectly perpetuating stereotypes about women for the 
survival of patriarchal society. The memes show the general mindset of people about women. These memes fulfill patriarchal Pakistani ideology about women. Women portrayal in memes may serve as expectations from Pakistani society as they are purposefully constructed and circulated on social media, especially Facebook. Results of this study confirm that importance of memes and its impacts on people will continue to grow as their popularity and social media rises.

\section{Conclusion}

This study aimed to explore women representation in Facebook memes in Pakistani context. This study has investigated how Pakistani women are linguistically and visually codified in the memes. It is found that women are represented negatively in the memes of Pakistani Facebook pages. The data analysis shows that negative representation of women is not only codified linguistically, but it is also enriched and created visually. The words clearly show that women depiction in the memes is negative. By connecting image with text, the memes represent negative image of women. Overall, women are linguistically and visually represented negatively in the memes. It leads to the conclusion that negative representation of women is maintained on social media.

\section{Recommendations}

Based on the findings this research suggests some recommendations for eliminating stereotypes and negativity about women. There is a need to create awareness to challenge stereotypes and negativity about women. It is necessary to teach the young children by educating and raising awareness that stereotypes have severe effects, which lead to the gender violence against women. There is a strong need to change the mindset of people through education. If people, especially males, are well educated, such biased and sexist ideologies could be eliminated. Both male and female gender should respect each other for pluralism. People, especially young ones, should be provided with knowledge and tools for resisting stereotypical content and practices. Moreover, it is recommended that addressing the effects of stereotyping in society, such as gender violence against women, may raise awareness to people. Training the socializing agents such as teachers, parents, coaches, and religious leader might also help for the eradication of such stereotypes and negativities about women. 


\section{References}

Aboulhosn, S. (2020). 18 Facebook statistics every marketer should know in 2020. https://sproutsocial.com/insights/facebook-stats-for-marketers/

Alphapro. P. (2018).Pakistan Social Media Stats 2018. https://alphapro.pk/pakistan-socialmedia-stats-2018/

Davison, P. (2012). The language of internet memes. The social media reader, 120-134.

Dawkins, R. (1976). The selfish gene New York: Oxford University Press. DawkinsThe Selfish Gene1976.

Ding, Z. (2015). The Internet Memes as a Rhetorical Discourse: Investigating Asian. Asian Americans' Identity Negotiation. https://etd.ohiolink.edu/!etd.send_file?accession=bgsu1429219266\&disposition=inli ne

Drakett, J., Rickett, B., Day, K., \& Milnes, K. (2018). Old jokes, new media-Online sexism and constructions of gender in Internet memes. Feminism \& Psychology, 28(1), 109-127.DOI: $10.1177 / 0959353517727560$

Fairclough, N. (2001). Language and power. Pearson Education.

Irfan, H. (2021). The Negative Role of Social Media to Create Anxiety Among University Students Amidst COVID-19. Global Mass Communication Review, VI (I),254-263. ISSN:2709-9458

Jahedi, M., Abdullah, F. S., \&Mukundan, J. (2014). An overview of focal approaches of critical discourse analysis. International Journal of Education and Literacy Studies, 2(4), 28-35

Kress, G. (2009). Multimodality: A Social Semiotic Approach to Contemporary Communication. Routledge.

Machin, D., \& Mayr, A. (2012). How to Do Critical Discourse Analysis: A Multimodal Introduction. SAGE.DOI: 10.1080/07268602.2015.1033673

Rakib, M. I. H. (2019). Name A More Iconic Duo, I'll Wait: Exploring the Role of Humour in Bangladeshi Internet Meme Culture (Doctoral dissertation, Mount Saint Vincent University).

Shifman, L. (2013). Memes in a digital world: Reconciling with a conceptual troublemaker.Journal of computer-mediated communication, 18(3), 362-377. DOI:10.1111/jcc4.12013

Shifman, L. (2014). Memes in digital culture. MIT press.

Siddiqui, N., Bains, A., Mushtaq, A., \& Aleem, S. (2018). Analysing Threads of Sexism in New Age Humour: A Content Analysis of Internet Memes. Indian Journal of Social Research, 59(3), 355-367.

Vahid, H., \&Esmae'li, S. (2012). The power behind images: Advertisement discourse in focus. International journal of Linguistics, 4(4), 36 
Exploring Women Representation in Meme Discourse: A Multimodal Critical Discourse Analysis of Selected Memes from Pakistani Facebook Pages

Van Dijk, T. A. (2001). 18 Critical discourse analysis. The handbook of discourse analysis, 349-371

Van Leeuwen, T. (2015). 21 Multimodality. Discourse Analysis, 447. https://books.google.com.pk/books?hl=en\&lr=\&id=B45FDwAAQBAJ\&oi=fnd\&pg=PA 447\&ots=Dy_PIqP2bS\&sig=f6euzKkFhXuVirvE12UW7zY3pXs 